NEWS

\title{
Stem cells derived from 'dead' human embryo
}

It has no brain, heart or nervous system. So how can researchers tell when an embryo has died? That question is likely to become a focus of debate, as scientists search for ways to create 'ethical' human embryonic stem cells.

Many researchers are investigating methods for deriving such cells without destroying human embryos. Now, one group claims to have developed human embryonic stem cells from a very young embryo that had already died.

Miodrag Stojković, who led the project at the University of Newcastle upon Tyne, UK, believes his technique may be acceptable to governments in countries such as Germany and the United States. Laws in these countries restrict the use of embryonic stem-cell lines owing to concerns about killing potential humans.

Whether or not the method is judged as harmless will probably depend on whether the lives of such embryos have indisputably ended. "It will intensify the debate over how to define the death of an embryo, because now there is more at stake," says Thomas Murray, president of the Hastings Center, a bioethics research institute in Garrison, New York.

During in vitro fertilization (IVF), well over half of human embryos arrest (stop dividing naturally), and are therefore unsuitable for transfer into women. Stojković, now a deputy director of the Prince Felipe Research Centre in Valencia, Spain, used 161 embryos donated by women in two local IVF clinics in his study, published online last week (X. Zhang et al. Stem Cells doi:10.1634/stemcells.2006-0377; 2006). Of these embryos, 29 were developing normally until cells were extracted, 119 arrested 3-5 days after fertilization, and 13 arrested 6-7 days after fertilization.

Arrested embryos were monitored for 24 to 48 hours, to check that none of the cells they contained started dividing again. In an IVF clinic, such embryos would meet the standard embryologist's criteria for having terminally arrested, and would typically be thrown away. Even in Italy, which has particularly restrictive laws stating that embryos cannot be destroyed and that all embryos created during IVF must be implanted, embryos which have arrested in this way are discarded.

The team derived healthy human embryonic stem-cell lines from eight of the normally developing embryos, one of the late-arrested embryos and none of the early-arrested embryos. Although many of the cells in the arrested embryos had distorted shapes or damaged chromosomes, a few cells remained healthy. To coax these into growing, the researchers removed the 'zona pellucida' that sheaths the embryo, and

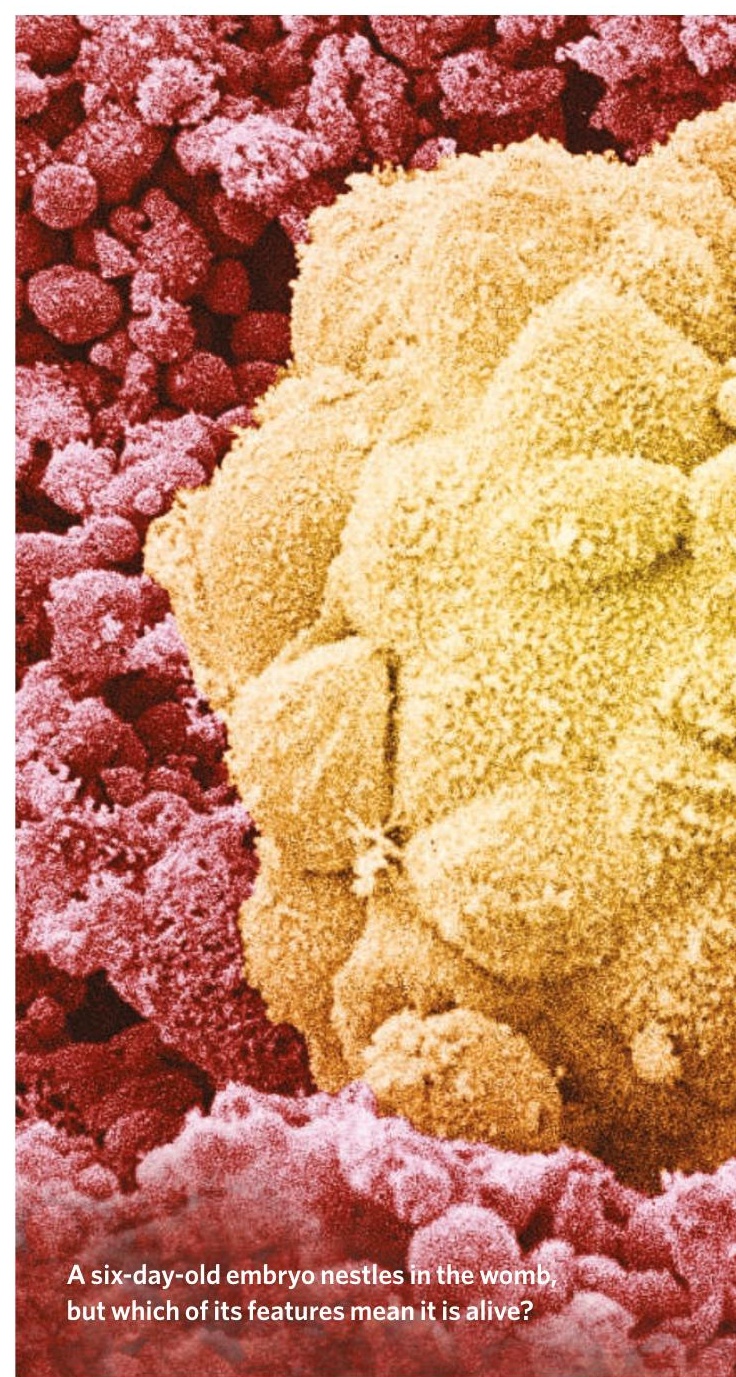

\section{Superconductivity research is down but not out}

"Reports of my death have been greatly exaggerated," Mark Twain allegedly said after his obituary was published prematurely. Hightemperature superconductivity physicists now know how he felt.

If current trends continue, research into high-temperature superconductivity (high $T_{\mathrm{c}}$ ) will come to a standstill some time between 2010 and 2015, according to a report by Andreas Barth and Werner Marx, respectively at FIZ Karlsruhe and the Max Planck Institute for Solid State Research in Stuttgart, Germany. That news hasn't gone down well.

Barth and Marx scoured databases owned by the Chemical Abstracts Services (CAS) and the physics and engineering abstracts service Inspec to find how interest in the field was holding up. They searched for all papers published and patents granted until the end of 2005 that involve alkaline earth cuprates containing rare earth elements. These materials show extremely low resistance to electricity at temperatures up to around $-200^{\circ} \mathrm{C}$. This is much warmer than temperatures normally associated with superconductors. But nobody has been able to work out how such high-temperature superconductors work.

Barth and Marx plotted the falling number of publications over time, then extrapolated the results to predict that the number of publications on these compounds will drop to zero between 2010 and 2015 "if no ground-breaking discoveries happen to occur".

Superconductivity scientists admit the field has slowed since the flurry of research that followed Georg Bednorz and Alex Müller's 1987 Nobel prize for their discovery of ceramic high-temperature superconductors. "There was a gold rush," says Jan Zaanen of Leiden University, the Netherlands. "It's a very deep problem - all the easy things have been done."

"All fields of condensed-matter physics undergo periods of ebb and flow," says Paul Grant, who has worked at IBM on high-temperature superconductors. "The general field of superconductivity is wide open."

After high-temperature superconductivity was discovered there was a huge spike in publications. Dreams of creating levitating trains, making a fortune and getting a Nobel prize for finding out how these systems work kept the field alive for a while. But as problems remained unsolved, people started to leave. "High $T_{c}$ made me 
